\title{
Effects of Teaching Metaknowledge and Journal Writing on Japanese University Students' EFL Writing
}

\section{Keiko Hirose and Miyuki Sasaki}

Aichi Prefectural University and Nagoya Gakuin University

Our previous research has identified five variables which influence L2 writing ability (Sasaki \& Hirose, 1996) in Japanese university English students. This study investigates the teachability of two of these variables, L2 metaknowledge and L2 writing experience, for English writing classes. Metaknowledge of English expository writing was taught to one group of students $(n=43)$, whereas a journal writing assignment was added to the metaknowledge instruction for the other group of students $(n=40)$. The effects of these two types of instruction on the students' subsequent writing were examined. Both groups significantly improved their metaknowledge, but the metaknowledge-instruction-only group did not improve their L2 writing significantly. In contrast, the group that received both metaknowledge instruction and the journal writing assignment significantly improved the mechanics of their L2 writing.

本研究は、横断的研究 (Sasaki \& Hirose, 1996) で抽出された日本人英語学習者の英作文力 の説明要因の教育効果を、維断的に検証するものである。五つの説明要因のうち、英語説 明文に関するメ夕知識と規則的に英作文を書く経験の 2 要因をとりあげ、英作文力に及ほ す教育効果を測定した。大学 1 年生の 1 グルーブには 1 学期間(12週間) メ夕知識を教え、別 のグループには同じメ夕知識教授に加えて、1 学期間定期的にできるだけ多量の英文を書 かせる指導を行った。指導後、両グループとも明示的なメ夕知識は增えたが、指導前後に 学生が書いた英作文を比較した結果、英文を書いたグループのみに作文のmechanicsの点で 向上がみられた。最後に、これらの結果を基に、今後の英作文指導とライティング研究に 与える示唆及び課題について考察した。

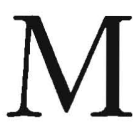

any studies have investigated variables which explain second language (L2) writing ability (e.g., Cumming, 1989; Raimes, 1987). Pedagogical application of the results of these studies should incorporate these explanatory variables into $\mathrm{L} 2 \mathrm{writing}$ instruction and, through longitudinal studies, subsequent research should examine the effects of this instruction on students' writing. Such longitudinal studies can then complement cross-sectional studies of L2 writing ability. 
Sasaki and Hirose (1996) have identified the following five factors as explanatory variables for Japanese university students' expository writing in English as a Foreign Language (EFL): (a) L2 proficiency; (b) first language (L1) writing ability; (c) L2 metaknowledge; (d) L2 writing experience; and (e) the use of good writers' writing strategies. Because the development of L2 proficiency in such areas as structure, vocabulary, listening, and L1 writing ability cannot generally be considered the main targets of L2 writing instruction, pedagogical implications arise mainly from the last three factors, which are directly connected to L2 writing. Among these three, the present study will focus on the factors of L2 metaknowledge and L2 writing experience and will investigate their teachability for Japanese university EFL students.

\section{Metaknowledge Instruction}

In this study metaknowledge of L2 writing is operationally defined as what is expected of paragraph-level expository writing in the target language. Because metaknowledge about L2 writing was found to have a significant influence on the quality of Japanese students' L2 writing (Sasaki \& Hirose, 1996), deliberately teaching it may therefore assist students in developing their L2 writing ability. Metaknowledge instruction consists of explicitly teaching paragraph elements such as the topic sentence, the body, and concluding sentence, and the types of organizational patterns (comparison and contrast, cause and effect, etc.). Such instruction fits well with the "current-traditional rhetoric approach," combining the "current-traditional paradigm" from L1 English composition instruction with contrastive rhetoric (see Silva, 1990, for details). Although the "current-traditional rhetoric approach" has been criticized for its strong focus on form, discouraging creative writing (Silva, 1990), it can be helpful to those students who do not have much knowledge about English paragraph structure. As Raimes (1983) points out, "even if students organize their ideas well in their first language, they still need to see, analyze, and practice the particularly 'English' features of a piece of writing" (p. 8). Thus, such an approach should be especially helpful for Japanese students, who are reported to use non-English organizational patterns when they write in English (Kobayashi, 1984). Although metaknowledge instruction for paragraph-level writing is presented in some composition textbooks (e.g., Hashiuchi, 1995), little empirical research has examined its effects on Japanese students' English writing. 


\section{English Journal Writing}

In previous research regular free writing practice has been found to be a major factor distinguishing "good" EFL writers from "weak" writers (Sasaki \& Hirose, 1996). Therefore it may be helpful to implement "journal writing" (JW) in EFL writing classes. JW has become an integral part of many English as a Second Language (ESL) composition courses in the U.S. (Spack \& Sadow, 1983) and is beginning to have a place in EFL writing courses in Japan as well (e.g., Casanave, 1993). However, most Japanese university students lack experience writing extensively in English. In junior and senior high school EFL classes L2 writing was mostly limited to translating sentences into English, and sentence-level grammatical accuracy was the major focus prior to university entrance (JACET Kansai Chapter Writing Teaching Group, 1995). Japanese university students, therefore, should be encouraged to write freely without much concern for accuracy in order to promote writing fluency.

Positive effects of $\mathrm{JW}$ instruction for Japanese university students have been noted by several researchers. Because students are writing in a non-threatening environment, they often report that they feel low anxiety and become comfortable writing extensively in their L2 (Kresovich, 1988). Additional studies suggest that JW improves writing quantity and quality. Ross, Shortreed, and Robb (1988) reported the development of fluency (measured by the number of T-units and words), especially in narrative compositions, over a one-year writing course. However, the effects of JW on writing quality have not been fully examined and mixed results have been reported. For example, Casanave (1994) noted conflicting results during a one-and-a-half year JW experience. Two thirds of her Japanese university EFL students improved their writing, but not all students produced longer, more complex sentences or more accurate language use. Thus, the effects of JW on quality should be investigated more fully.

JW is an individual student activity and is not considered a major constituent of a writing course. According to McCornick (1993), JW is used "as a supplementary exercise, not as the main activity in any language course" (p. 17) in a large Japanese university (see also Ross et al., 1988). These points justify a comparative study between students' writing samples from a writing course which incorporates JW and those from a similar course without a JW component, as Spack and Sadow (1983) have advocated. 


\section{The Present Study}

We conducted the present study to investigate whether explicit instruction on two of the variables shown to influence Japanese university students' EFL writing (metaknowledge and regular writing experience) can improve students' L2 expository writing over one semester. ${ }^{1}$ We compared instruction of only metaknowledge to instruction on metaknowledge combined with JW. We were not able to have a JW-only group as a control group because it was not possible to require the students to do JW regularly in non-composition courses. ${ }^{2}$

\section{Research Questions}

The present study explores three research questions:

1. Does formal instruction of metaknowledge have an effect on the development of students' L2 expository writing ability?

2. Does metaknowledge instruction combined with journal writing experiençe have an effect on the development of students' L2 expository writing ability?

3. Does metaknowledge instruction combined with journal writing experience have a greater effect on the development of students' L2 expository writing ability than metaknowledge-only instruction?

These three questions have the same follow-up question: If so, what aspect(s) of L2 writing show improvement on the basis of such instruction/ experience?

\section{Method}

\section{Participants}

A total of 83 Japanese university freshmen (20 men and 63 women) majoring in British and American Studies participated in the present study. Their average age was 18.3 years and they had studied English for an average of 6.4 years, mainly through controlled formal English education in Japan. The participants were students in four intact English writing classes at two universities. ${ }^{3}$ They were assigned to two groups, Groups 1 and 2, and were given the following instruction (see the Content of Instruction for details):

Group 1 ( $n=43 ; 11$ men and 32 women): Metaknowledge instruction only

Group 2 ( $n=40 ; 9$ men and 31 women): Metaknowledge instruction plus journal writing assignments 
The two groups were comparable in many ways. First, they were similar in their instructional/personal backgrounds. ${ }^{4}$ The results of chi-square analyses of responses to a questionnaire (for details of this questionnaire, see Sasaki \& Hirose, 1996) eliciting their instructional/personal writing backgrounds and their attitudes toward L1 and L2 writing revealed no significant differences between the two groups. In addition, they shared similar backgrounds in terms of L1/L2 writing instruction, and in the type and amount of L1/L2 writing. For example, the great majority of students $(95.3 \%$ of Group 1 and $97.5 \%$ of Group 2) had never learned "organizing a paragraph centered on one main idea" or "developing a paragraph so that the readers can follow it easily" (95.3\% and 95\%, respectively).

The two groups did not differ significantly in their attitude to either L1 or L2 writing. For example, in their responses to the question item "Do you like writing in L2?" 34.9\% of Group 1 chose "yes," and 62.8\% "neither like nor dislike it." Similarly, $25 \%$ of Group 2 chose "yes" and $67.5 \%$ "neither like nor dislike it." In other words, neither group of students had a negative attitude to L2 writing; only a few students (2.3\% of Group 1 and $7.5 \%$ of Group 2) answered they did not like L2 writing. Their responses to the question whether they liked L1 writing showed a similar tendency.

Furthermore, the two groups were similar in terms of their English language proficiency. They took the Structure section of the Comprehensive English Language Test for Learners of English (CELT) (Form A; Harris \& Palmer, 1986) and the Test of English as a Foreign language (TOEFL), and their English proficiency level was mostly intermediate [CELT Structure $M(S D)$ : Group $1=71.2$ (13.2); Group $2=70.8$ (14.1); TOEFL $M(S D)$ : Group $1=446.8$ (47.7); Group $2=440.5$ (66.0)]. The results of $t$-tests showed that the two groups' test scores were not significantly different (CELT Structure: $t=0.12, d f=81, p=0$.9; TOEFL: $t=$ $0.5, d f=81, p=0.62) .^{5}$

Finally, the two groups were similar in their L2 writing ability and metaknowledge about English expository writing. They wrote English compositions and took a metaknowledge test at the beginning of the writing courses (see the Data section below). The $t$-test results for scores on the English compositions and metaknowledge tests showed no significant differences between the two groups (English composition: $t=$ $0.84, d f=81, p=0.4$; metaknowledge: $t=-0.51, d f=81, p=0.61$; see Tables 3 and 4 for means and standard deviations).

\section{Content of Instruction}

All participants were given instruction on metaknowledge of English expository writing in their English writing classes. The classes met once 
a week for 90 minutes over a 12-week semester of the 1994 academic year. ${ }^{6}$ The two groups used the same textbook (Jimbo \& Murto, 1990), in which each chapter deals with one idea related to paragraph organization, such as the topic sentence. In every chapter, the book first presents a model paragraph to illustrate the target organizational pattern (e.g., time order, cause and effect, and classification) and then provides practice in analyzing other paragraphs. The textbook is written in English, including the explanation section. Students in Groups 1 and 2 spent in-class time in the same way with the textbook, and all activities were centered around the analysis of paragraphs based on the readings. When responding to exercises provided in the book, both groups of students underlined the topic sentence of the paragraphs they read. However, the metaknowledge instruction did not include practice producing topic sentences or writing original paragraphs.

In addition to studying paragraph organization, the students in Group 2 were assigned to write English journals regularly (at least four days a week) outside the class. Having been given such instructions as "Spend no less than 15 minutes when writing," "Try to write as much as you can about anything," and "Do not worry too much about spelling and grammar," the Group 2 students accumulated JW experience on a regular basis for 12 weeks. They were not instructed specifically to apply the learned metaknowledge to JW. Every week they counted the number of lines written per week and chose one day's entry for a teacher or a classmate to read and write questions and/or comments on the entry. They then spent approximately 5 to 10 minutes of the class time reading and giving written feedback to each other. This in-class activity was intended to raise the students' sense of an audience when they did JW. No correction was made of anything the students wrote. Students were told that only the amount of writing would be taken into consideration for their grades. On average, the Group 2 students wrote 487.2 words every week, with a range from 154.7 to 728.7 . In contrast, the students in Group 1 were not asked to write journals. Therefore, the main difference between the two types of instruction was that JW required work outside of class for Group 2.

\section{Data}

\section{Pre-and Post-compositions}

All participants wrote a 30-minute English composition at the beginning and at the end of the course. At the beginning the two groups were given the following L1 prompt to write about: 
There has been a heated discussion about the issue of "women and work" in the readers' column in an English newspaper. Some people think that women should continue to work even after they get married, whereas others believe they should stay at home and take care of their families after marriage. Now the editor of the newspaper is calling for the readers' opinions. Suppose you are writing for the readers' opinion column. Take one of the positions described above, and write your opinion.

This task was the same as that used in our previous research (Sasaki \& Hirose, 1996). At the end of the composition course, both groups wrote a second English composition on the following L1 prompt:

There has been a heated discussion about the issue of "university students and part-time jobs" in the readers' column in an English newspaper. Some people think that students should not have parttime jobs, whereas others believe they should work part-time. Now the editor of the newspaper is calling for the readers' opinions. Suppose you are writing for the readers' opinion column. Take one of the positions described above, and write your opinion.

For the pre- and post-compositions, we chose different topics to avoid possible influences of participants' thinking about the first topic over time. We considered that the two topics were familiar to the students (i.e., topics concerning their mothers and themselves respectively), and comparable in difficulty. We did not inform the participants about the topic beforehand for either task and they were not allowed to use a dictionary. By comparing the two compositions, we were able to examine the teaching effects of the two types of instruction.

Each of the two researchers scored the pre- and post-compositions, according to Jacobs, Zinkgraf, Wormuth, Hartfiel, and Hughey's (1981) ESL Composition Profile. Ratings were assigned for the five criteria of content, organization, language use, vocabulary, and mechanics. ${ }^{7}$ Each participant's composition score was the sum of the two researchers' scores, with a possible range from 68 to 200 points. (See Appendix 1 for sample pre- and post-compositions by the same writer.)

\section{Test of Metaknowledge of English Expository Writing}

Before and after the participants received the instruction, we also tested their knowledge of such notions as coherence, unity, topic sentence, and organization of English expository writing. As had been done previously (Sasaki \& Hirose, 1996), the test was developed as a criterion-referenced measure with its content centered on the course objectives of the English writing courses in which the data were collected. The major purpose for developing the test was to measure the students' 
knowledge of the target content area (i.e., their metaknowledge of English expository writing), not to measure their ability to produce texts. The test was given in Japanese and was composed of 12 items divided into the following three sections: (a) reading several statements about the concepts of coherence, topic sentence, and conclusion, and selecting the most appropriate one to describe English expository writing (10 items); (b) choosing the better English paragraph from two alternatives ( 1 item); and (c) choosing the best of three alternative paragraphs ( 1 item) (see Appendix 2 for sample test items). ${ }^{8}$

Only the compositions from students who attended both data-collecting sessions were used for the present analyses. This resulted in six students not being included and a total number of 83 participants.

\section{Reliability}

We calculated inter-rater reliability (the Pearson correlation coefficient) for the five subscores and total scores of the pre- and post-English compositions (see Table 1). For both the pre- and post-metaknowledge tests, calculating any internal consistency estimates would not be appropriate because they were criterion-referenced (see Sasaki \& Hirose, 1996). Therefore, we obtained the difference index (DI), one of the recommended reliability estimates for a criterion-referenced test (CRT), for each item. The DI shows "the degree to which a CRT item is distinguishing between the students who know the material or have the skill (sometimes called masters) and those who do not (termed nonmasters)" (Brown, 1989, p. 72). Following Brown (1989), we considered items acceptable which had a DI value of higher than 0.10 .

\section{Data Analysis}

For Research Questions 1 and 2, we compared the pre- and postcompositions (in terms of the five subscores and total scores) and the pre- and post-metaknowledge test scores within each group. We tested their differences for significance using paired $t$-tests. For Research Question 3, we compared the two groups' post-compositions. We conducted $t$-tests to check for statistically significant differences between the two groups' writing. Because we employed multiple $t$-tests, we made a Bonferroni adjustment to avoid inflated Type I errors, errors that occur when a true null hypothesis is rejected. (See Tabachnick \& Fidell, 1996, for an explanation of the Bonferroni adjustment.) Because we made 20 comparisons in all, we divided the alpha level of 0.05 for the study by the number of comparisons (i.e., $0.05 / 20$ ), and accepted only those $t$ tests that were below the 0.0025 level as significant. 


\section{Results and Discussion}

\section{Reliability}

Table 1 presents inter-rater reliability estimates for the five criteria of content, organization, language use, vocabulary, mechanics, and total scores for the pre- and post-course compositions. Reliability estimates for the five variables were generally high except for mechanics. Mechanics had relatively low reliability $(0.57-0.67)$ because the full score was small (10) and did not show enough variation among the students (see Tables 3 and 4 for the small SDs for mechanics).

The DI values for all metaknowledge test items except one were acceptably high for both groups (see Table 2), indicating that the test was reliable as a CRT. The small DI values of Item 11 for both groups suggest that this item measured a construct that had already been mastered by the students before the instruction began (see Q11 in Appendix 2). This item thus should be removed when the test is revised in the future.

Table 1: Inter-rater Reliability Estimates for 12 Variables

\begin{tabular}{lcc}
\hline Variable & Group 1 $(n=43)$ & Group 2 $(n=40)$ \\
\hline Pre-comp. Total & 0.87 & 0.91 \\
Pre-comp. Content & 0.87 & 0.91 \\
Pre-comp. Organization & 0.81 & 0.69 \\
Pre-comp. Vocabulary & 0.79 & 0.75 \\
Pre-comp. Language Use & 0.72 & 0.77 \\
Pre-comp. Mechanics & 0.57 & 0.59 \\
& & \\
Post-comp. Total & 0.96 & 0.91 \\
Post-comp. Content & 0.91 & 0.80 \\
Post-comp. Organization & 0.90 & 0.74 \\
Post-comp. Vocabulary & 0.80 & 0.75 \\
Post-comp. Language Use & 0.86 & 0.80 \\
Post-comp. Mechanics & 0.67 & 0.65 \\
\hline
\end{tabular}

\section{Research Question 1}

Research Question 1 was concerned with the development of Group 1 students' L2 writing ability. The results of paired $t$-tests for pre- and post-English composition subscores and total scores and for pre- and post-metaknowledge scores in Group 1 demonstrated that there was a significant gain in metaknowledge $(t=-13.46, p<0.0025)$ (see Table 3). 
Table 2: Difference Indices for the Metaknowledge Test

\begin{tabular}{lcc}
\hline Item & Group 1 & Group 2 \\
\hline 1 & 0.58 & 0.55 \\
2 & 0.44 & 0.35 \\
3 & 0.37 & 0.45 \\
4 & 0.32 & 0.37 \\
5 & 0.24 & 0.17 \\
6 & 0.47 & 0.27 \\
7 & 0.67 & 0.52 \\
8 & 0.33 & 0.37 \\
9 & 0.19 & 0.28 \\
10 & 0.47 & 0.53 \\
11 & 0.02 & 0.00 \\
12 & 0.34 & 0.33 \\
\hline
\end{tabular}

Difference Index $(D I)=$ The item difficulty (the proportion of participants who answered a given item correctly) for the Post-Metaknowledge Test minus the item difficulty for the Pre-Metaknowledge Test

However, there was no significant gain in any of the five categories of composition evaluation: content $(t=1.27, p=0.21)$, organization $(t=$ $0.43, p=0.67)$, vocabulary $(t=0.40, p=0.70)$, language use $(t=0.00, p$ $=1.00)$, mechanics $(t=-2.75, p=0.009)$, or total composition score $(t=$ $0.34, p=0.73$ ). After the instruction, students in Group 1 improved in terms of metaknowledge of English expository writing. It turned out, however, that their improved metaknowledge did not help their actual writing in any of the five criteria (content, organization, language use, vocabulary, and mechanics) examined. Although the content of metaknowledge instruction was related to organizational patterns in English paragraphs, it seems that learned metaknowledge did not translate into the ability to use that knowledge in organizing the text during actual writing (see the section below).

In summary, teaching metaknowledge solely by analyzing and studying model paragraphs did not improve students' writing ability. Instruction using models alone proved insufficient to improve students' L2 writing. L1 studies as well (see Smagorinsky, 1991) suggest that instruction solely through models does not improve students' writing processes. In order for metaknowledge instruction to be effective, we may need a longer time than one semester, or may need to combine it with other kinds of instruction. We now turn to the combination of metaknowledge and JW in Research Question 2. 
Table 3: Pre- and Post-English Composition and Metaknowledge Scores for Group 1

\begin{tabular}{lcrrrrr}
\hline & \multicolumn{2}{c}{ Pre-composition } & \multicolumn{3}{c}{ Post-composition } & \\
Measure (total possible) & $M$ & $S D$ & $M$ & $S D$ & $t$ \\
\hline Composition Total (200) & 142.0 & 18.8 & 141.3 & 17.7 & 0.34 \\
Content (60) & 45.6 & 5.4 & 45.0 & 5.4 & 1.27 \\
Organization (40) & 29.2 & 4.6 & 28.9 & 4.0 & 0.43 \\
Vocabulary (40) & 27.9 & 3.8 & 27.7 & 3.9 & 0.40 \\
Language Use (50) & 31.3 & 5.2 & 31.3 & 5.0 & 0.00 \\
Mechanics (10) & 8.0 & 0.96 & 8.5 & 1.18 & -2.75 \\
Metaknowledge (12) & 6.70 & 2.25 & 11.14 & 0.97 & $-13.46^{*}$ \\
\hline
\end{tabular}

$d f=42,{ }^{*} p<.0025$

\section{Research Question 2}

Research Question 2 was related to the development of Group 2 students' L2 writing ability. Results of paired $t$-tests for pre- and post-composition subscores and total scores, and for pre- and post-metaknowledge test scores in Group 2 showed that there were significant gains in metaknowledge $(t=-10.33, p<0.0025)$ and also mechanics $(t=-3.66$, $p<0.0025$ ) (see Table 4). Although the latter result should be treated with some caution because of the low reliability estimates for mechanics (recall Table 1), it still shows one aspect of the improvement that Group 2 students made on their post-composition. Mechanics was the only aspect of their post-compositions which improved statistically. Unlike the case of metaknowledge-only instruction, therefore, metaknowledge instruction combined with JW helped Group 2 students improve the spelling, capitalization, punctuation, paragraphing, and handwriting, criteria included in Jacobs et al.'s (1981) mechanics. This improvement may have been derived from the metaknowledge instruction which included reading paragraphs, but was more likely from actual writing practice.

On the other hand, although some evidence of improvement was seen, significant differences were not found in the four criteria of content $(t=-0.90, p=0.37)$, organization $(t=0.59, p=0.56)$, vocabulary $(t=$ $-2.74, p=0.009)$, language use $(t=-2.50, p=0.017)$, or on total composition score $(t=-2.27, p=0.029)$, just as in the case of Group 1 .

Regarding content, the nonsignificant result is not a matter for concern because the topics for the pre- and post-compositions were different, and one of the ESL Composition Profile criteria for content is how much knowledge is presented about the assigned topic (Jacobs et al., 
Table 4: Pre- and Post-English Composition and Metaknowledge Scores for Group 2

\begin{tabular}{lccccc}
\hline & \multicolumn{3}{c}{ Pre-composition } & \multicolumn{3}{c}{ Post-composition } & \\
Measure (total possible) & $M$ & $S D$ & $M$ & $S D$ & $t$ \\
\hline Composition Total (200) & 138.6 & 17.3 & 143.4 & 17.3 & -2.27 \\
Content (60) & 45.1 & 6.0 & 45.7 & 5.2 & -0.90 \\
Organization (40) & 28.6 & 4.2 & 28.9 & 3.8 & -0.59 \\
Vocabulary (40) & 27.0 & 3.7 & 28.4 & 3.8 & -2.74 \\
Language Use (50) & 30.4 & 4.0 & 32.0 & 4.6 & -2.50 \\
Mechanics (10) & 7.7 & 0.96 & 8.5 & 1.2 & $-3.66^{*}$ \\
Metaknowledge (12) & 6.95 & 2.28 & 11.18 & 0.98 & $-10.33^{*}$ \\
\hline
\end{tabular}

$d f=39,{ }^{*} p<.0025$

1981, p. 92). The students might have had a similar degree of knowledge about the two topics. In contrast, the nonsignificant result concerning organization does necessitate discussion. Gained metaknowledge again was not reflected in students' actual writing in terms of organization. This is hardly surprising because what the students practiced through JW was mainly expressive or narrative writing, not expository writing. They wrote mostly about themselves; for example, what they did, thought of, or felt on that day. Writing about oneself in terms of feelings and personal experience is not an alien concept for Japanese students because they have done that in their L1 (Murai, 1990). Expressive writing in L1 is quite prevalent in Japan, especially at the elementary school level (e.g., Kokugo Kyoiku Kenkyusho, 1988). The participants probably did not find it difficult to adapt themselves to writing L2 journals, just like Liebman's (1992) Japanese ESL students at a U.S. university. Such free writing, however, does not require much organization because students can write whatever comes to their mind without worrying about form (e.g., grammar, spelling) or bothering to organize their thoughts (Leki, 1985). Thus, the knowledge of English organizational patterns students gained through metaknowledge instruction was unlikely to be used or transferred when they did JW.

It may also be the case that, given a 30-minute time limit, neither Group 1 nor Group 2 students could make use of their learned metaknowledge during actual writing. Without the time constraint, they might have been able to use metaknowledge to produce writing with better organization. Comparing pre- and post-essays, Bereiter and Scardamalia (1987) found that the time allotment (30 minutes) "obviously did not allow the extended plan-development that experimental-group students had been learning to 
do, but at which they had not yet developed much facility" (p. 313). Thus, in order to examine whether students are hindered from using metaknowledge under time pressure, we should provide time-free writing conditions to students and also compare their writing processes, as done in Bereiter and Scardamalia (1987).

The overall quality and use of vocabulary (range, word/idiom choice and usage, register, etc.) and language use (defined to include sentence construction, tense, agreement, number, etc. by Jacobs et al., 1981) were not found to be significantly improved either. Although a 12 -week JW experience with explicit metaknowledge instruction was not sufficient to significantly improve linguistic skills involving lexical and syntactic control in English writing, it appears to have had some influence (i.e., Group 2 students' post-composition scores on vocabulary and language use were higher than their pre-composition scores). The results of the present study suggest that skills regarding spelling, punctuation, or paragraphing are learned early compared with other skills concerning vocabulary, language use, and organization. It is not certain from our results whether or not these students simply need more writing experience to improve the latter skills. Casanave's (1993) EFL Japanese students self-reported that three semesters of JW developed their organizational skills along with other skills.

In summary, combination of metaknowledge instruction and JW contributed to improving the students' writing in terms of mechanics. The results may suggest that this combination of instruction is promising for $\mathrm{L} 2$ writing instruction, especially when the allowed course length is short. It is difficult, however, to determine conclusively which component, metaknowledge instruction or JW experience, was more helpful in improving students' mechanics. We turn to this issue in Research Question 3.

\section{Research Question 3}

Research Question 3 was related to the comparison between Groups 1 and 2. In the English compositions written before the instruction, there were no significant differences between the two groups (recall the Participants section), although the metaknowledge-instruction-only group's mean pre-composition score was higher than that of the metaknowledge plus JW group (142.0 vs. 138.6). In order to determine which of the two instruction types was more effective, a between-group comparison was made on the post-composition scores. The $t$-test results showed no significant difference between Group 1 and 2 on post-composition scores in any aspect examined (content $[t=-0.64, p=0.53]$, organization $[t=0.09, p=0.93]$, vocabulary $[t=-0.78, p=0.44]$, language use $[t=-0.71, p=0.48]$, mechanics $[t=-0.04, p=0.97]$, total composition 
score $[t=-0.49, p=0.62])$. Thus, we cannot claim at this point that either of the two types of instruction had a greater effect on students' writing.

Although the mean post-composition score for Group 2 was higher than that of Group 1, the difference was not statistically significant. Recall that one aspect of the composition scores for Group 2, mechanics, significantly improved after the instruction (Table 4), whereas the composition scores for Group 1 did not (Table 3). However, the improvement by Group 2 was not large enough for the group's mean post-composition score to be significantly better than that of Group 1, probably because the mean precomposition score of Group 1 was substantially (but not significantly) higher than that of Group 2 before the instruction began.

The results, however, do not downgrade the writing instruction Group 2 received. Only one semester of metaknowledge plus JW instruction may not be long enough to be significantly more effective than metaknowledgeonly-instruction in promoting writing gains. Reporting on positive effects of JW on Japanese university students' L2 writing, McCornick (1993) claims that "time is the crucial condition" (p. 10), and further suggests that most students would require JW for three semesters to improve their writing. Given an appropriate length of time, as Spack and Sadow (1983) suggest, expressive writing experience might eventually lead students to be better expository writers. Organization might gradually improve if students keep up JW longer than a semester. Alternatively, not only explicit metaknowledge instruction but also experience such as more controlled paragraph or essay writing may be necessary for students to be able to use learned metaknowledge to improve their expository writing.

Suggesting that personal writing helps to develop academic writing skills, Mlynarczyk (1991) recommends that ESL writing instruction should start with personal writing. EFL students should benefit from such personal writing experience too.

\section{Conclusion}

As a follow-up study to the previous cross-sectional study on the factors contributing to L2 writing ability (Sasaki \& Hirose, 1996), the present longitudinal study investigated the effects of teaching two variables, metaknowledge and writing experience (operationalized as JW) over a semester. The results revealed that (a) metaknowledge instruction alone was insufficient to help students improve their writing, (b) metaknowledge instruction combined with JW improved EFL Japanese university students' facility in mechanics, and (c) the teaching effects of metaknowledge combined with JW were not great enough to make a significant difference in writing ability as opposed to those of 
metaknowledge-only instruction. The second finding seems the most encouraging and suggestive. The other two, however, do not imply that metaknowledge or JW is ineffective in improving EFL students' L2 writing. In actuality, both should be incorporated in EFL writing instruction, not only at university level but also at secondary school level, and in combination with other writing activities such as more structured paragraphs/essays/papers. As pointed out by Raimes (1991), "instructional balance" is the key to the teaching of writing.

Although the results of the present study provide some pedagogical implications for EFL writing instruction, the relatively small sample size limits generalizability, and thus, these findings should be confirmed with a larger sample. It is also important to confirm the results with different groups of students, such as those with higher or lower English proficiency levels. Despite the limitations, the present study indicates directions for further research.

First, to ascertain the effects of metaknowledge instruction and JW experience on L2 students' writing, we should conduct longitudinal studies for a period longer than one semester, for example, over a one-, two-, three-, or four-year period. Such follow-up studies may require diverse means to measure teaching effects on students' L2 writing, as suggested by Casanave (1994). Improvement should therefore be measured in various ways, not solely by numerical indices of writing quality. For example, it should be determined whether and how students' L2 writing processes are influenced by such instruction (see Smagorinsky, 1991, for L1 research).

Second, the present study suggests that the effects of instruction vary according to the individual student. Under both types of instruction, some students improved their writing, whereas others did not (see Appendix 1 for sample compositions by one of the former group). To discover the salient characteristics of those who have improved, future studies should use observation and interviews. Such qualitative studies would complement the kind of quantitative research exemplified by the present study.

Third, the effects of teaching writing strategies such as planning and revising should also be investigated because such instruction may also influence writing processes. Based on L1 composition instruction using a list of cues which stimulated self-questioning during planning, Scardamalia, Bereiter, and Steinbach (1984) reported some reflective change in students' writing processes (see also Bereiter \& Scardamalia, 1987). Furthermore, Smagorinsky (1991) used protocol analysis to examine the effects of teaching brainstorming or revising strategies on the writing processes of L1 students. In contrast, few studies have been conducted on the effects of writing strategy instruction on L2 writing. 
Finally, we should explore the issue of applying metaknowledge to the writing process and performance, and determine whether L2 writing skills acquired through JW are transferable/transferred to other writing, such as exposition.

\section{Acknowledgments}

We would like to thank. Theresa Austin, Carol Rinnert, and the anonymous reviewers of JALT Journal for their insightful comments and suggestions regarding this paper.

Keiko Hirose is Professor at Aichi Prefectural University. Her research interests include L2 writing development and comparing L1 and L2 writing processes.

Miyuki Sasaki is Professor at Nagoya Gakuin University. Her research interests include L2 writing assessment and interlanguage pragmatics.

\section{Notes}

1. Because the writing courses were only one semester in length, we could not conduct a longer study of writing development using the two instructional treatments.

2. Some might argue that it is possible to assign JW to students in nonwriting English courses, thus allowing a control group. However, increasing the amount of work required for the students' other English courses might give students the perception that they were being overloaded with assignments. This could have a negative impact on their completion of the regular assignments for the course as well as on their completion of JW. Furthermore, the JW assignment and peer feedback activities would be difficult to implement in nonwriting English courses.

3. The authors each taught two classes: one metaknowledge-instruction-only, and one metaknowledge-instruction plus JW.

4. We examined the participants' L1 and L2 writing background using the questionnaire described in Sasaki and Hirose (1996). The questions asked what types of writing (e.g., translating individual Japanese sentences into English, writing more than one paragraph) and how much writing the participants did prior to entering their universities.

5. The internal consistency estimates calculated by Kuder-Richardson formula 20 for the CELT Structure were high for both Groups 1 and 2 (0.89 and 0.90, respectively). The reliability of the TOEFL subsections could not be calculated because the test was scored by an external organization, and the itemlevel performance was not given to the authors.

6. All participants were taking five other English courses (reading, speaking/ listening, etc.) concurrently.

7. We used this profile because we believe that the organization component of the profile is related to metaknowledge instruction. We also believe that other categories such as vocabulary and language use are related to JW experience. 
8. We used test items (a) created for our previous research (Sasaki \& Hirose, 1996), whereas we based the designs of test items (b) and (c) on the coursebook (Jimbo \& Murto, 1990).

\section{References}

Bereiter, C., \& Scardamalia, M. (1987). The psychology of written composition. Hillsdale, NJ: Lawrence Erlbaum.

Brown, J. D. (1989). Improving ESL placement tests using two perspectives. TESOL Quarterly, 24, 65-83.

Casanave, C. P. (1993). Student voices: The insiders speak out on journal writing. In C. P. Casanave (Ed.), Journal writing: Pedagogical perspectives (pp. 95115). Institute of Language and Communication, Keio University, SFC (Shonan Fujisawa Campus).

Casanave, C. P. (1994). Language development in students' journals. Journal of Second Language Writing, 3, 179-201.

Cumming, A. (1989). Writing expertise and second-language proficiency. Language Learning, 39, 81-141.

Harris, D. P., \& Palmer, L. A. (1986). CELT: Examiners' instructions and technical manual. New York: McGraw-Hill.

Hashiuchi, T. (1995). Paragurafu raitingu nyumon (An introduction to paragraph writing). Tokyo: Kenkyusha.

JACET Kansai Chapter Writing Teaching Group (Ed.) (1995). Daigaku ni okeru eisakubun shido no arikata: Eisakubun jittai chosa no bokoku [English writing instruction at the university levels in Japan: A survey of English writing instruction]. Kyoto: Authors.

Jacobs, H. L., Zinkgraf, S. A., Wormuth, D. R., Hartfiel, V. F., \& Hughey, J. B. (1981). Testing ESL composition: A practical approach. Rowley, MA: Newbury House.

Jimbo, H., \& Murto, R. B. (1990). Paragraphs that communicate: Reading and writing paragraphs. Tokyo: Linguaphone.

Kobayashi, H. (1984). Rhetorical patterns in English and Japanese. Unpublished doctoral dissertation, Teachers College, Columbia University, New York.

Kokugo Kyoiku Kenkyusho (Ed.) (1988). Kokugo kyoiku kenkyu daijiten [Dictionary of Japanese language education]. Tokyo: Meiji Tosho.

Kresovich, B. M. (1988). The journal assignment in composition class at a Japanese university. Bulletin of the College of Education, University of the Ryukyus, $33,71-83$.

Leki, I. (1985). Linking writing journals to writing in the ESL classroom: Part II. TECFORS, 8, 2-6.

Liebman, J. D. (1992). Toward a new contrastive rhetoric: Differences between Arabic and Japanese rhetorical instruction. Journal of Second Language Writing, 1, 141-165.

McCornick, A. (1993). Journal writing and the damaged language learner. In C. P. Casanave (Ed.), Journal writing: Pedagogical perspectives (pp. 6-17). Institute of Language and Communication, Keio University, SFC (Shonan Fujisawa Campus). 
Mlynarczyk, R. (1991). Is there a difference between personal and academic writing? TESOL Journal, 1, 17-20.

Murai, M. (1990). Sakubun shido no riron [Theories of composition instruction]. In K. Otsuki (Ed.) Kokugokyouikugaku [Japanese language pedagogy] (pp. 145-152). Tokyo: Fukumura Shuppan.

Raimes, A. (1983). Techniques in teaching writing. New York: Oxford University Press.

Raimes, A. (1987). Language proficiency, writing ability, and composing strategies: A study of ESL college student writers. Language Learning, 37, 439-468.

Raimes, A. (1991). Instructional balance: From theories to practices in the teaching of writing. In J. E. Alatis (Ed.) Georgetown University round table on languages and linguistics 1991 (pp. 238- 249). Washington, DC: Georgetown University Press.

Ross, S., Shortreed, I. M., \& Robb, T. N. (1988). First language composition pedagogy in the second language classroom. RELC Journal, 19, 29-48.

Sasaki, M., \& Hirose, K. (1996). Explanatory variables for EFL students' expository writing. Language Learning, 46, 137-174.

Scardamalia, M., Bereiter, C., \& Steinbach, R. (1984). Teachability of reflective processes in written composition. Cognitive Science, 8, 173-190.

Silva, T. (1990). Second language composition instruction: Developments, issues, and directions in ESL. In B. Kroll (Ed.), Second language writing: Research insights for the classroom (pp. 11-23). Cambridge: Cambridge University Press.

Smagorinsky, P. (1991). The writer's knowledge and the writing process: A protocol analysis. Research in the Teaching of English, 25, 339-364.

Spack, R., \& Sadow, C. (1983). Student-teacher working journals in ESL freshman composition. TESOL Quarterly, 17, 575-593.

Tabachnick, B. G., \& Fidell, L. S. (1996). Using multivariate statistics (3rd ed.). New York: HarperCollins College Publishers.

(Received November 19, 1997; revised January 12, 2000)

\section{Appendix 1 \\ Sample Pre- and Post-compositions* by the Same Student}

\section{Pre-composition on "women and work"}

I agree to the idea that it is good for married women to get jobs. because I think if they are at home in an all day they will be losing their vitality, and they may become a boring person.

There may be some useful persons for the society in married women. It is very weistful not to let them work, this is also one of the reason I think married women had better work. I think it is important to regard everyone not as a man or a woman but a individual. Rights everyone has are equal, therefore even married women should be given rights and chances that men has. 
Post-composition on "university students and part-time jobs"

I think university students had better have a part-time job. Acctually university students go to the university to study, but is there reason that they shouldn't have a part time job? Some people may say that having a part time job keeps the university student from studying, but I don't think so. I think they manage to study doing a part-time job.

There are many advantages in doing a part-time job. For example, they can get money, so they can buy books for studying or they can pay an expence of university. If they have some money they can do most of what they want to do, so they will become more active. They can also learn part of society. They know how hard it is to earn money, so they may thank for their parents who have brought up them. They may make friends, and they may have a confidence of themselves because they can do jobs which are given. They may find what they really want to do in part-time jobs.

There are much more benefits in doing a part-time job than disadvantage, so I think university students had better have a part-time job.

*Spelling and grammar errors are the student's.

\section{Appendix 2}

\section{Excerpts of the Test of Metaknowledge of English Expository Writing *}

I. Read the following statements concerning English expository writing and choose the one which matches your knowledge.**

Q1. (a) An English paragraph usually has one sentence which summarizes the whole paragraph, but the writer can write other things which are not expressed in that sentence if they are related to the main topic.

(b) An English paragraph has one sentence which summarizes the whole paragraph, and the writer has to write only those which are related to the main idea.

(c) An English paragraph does not usually have one sentence which summarizes the whole paragraph, and the writer can write whatever s/ he likes.

(d) I do not know any of the above.

Q3. (a) The first part of an English paragraph is the introduction, where the writer begins with a general topic related to the main theme, and gradually moves on to the main topic in the later part.

(b) An English paragraph usually has a summarization of the main point in the first part, followed by explication and/or exemplification in the later part.

(c) An English paragraph does not have a fixed pattern.

(d) I do not know any of the above.

Q4. (a) An English paragraph is developed along such organizational patterns as time, space, cause and effect, or comparison and contrast.

(b) An English paragraph does not have fixed patterns of development, so 
that the writer develops a paragraph freely as $s /$ he wants.

(c) I do not know any of the above.

Q7. (a) The writer in English develops his/her argument freely without considering the readers much.

(b) The writer in English writes for the readers to follow his/her argument easily.

(c) I do not know any of the above.

Q9. (a) Regarding English paragraphs arguing for or against a certain opinion, the writer tends to state both positions without specifying his/her own position.

(b) In opinion-statement paragraphs in English, the writer tends to specify his/her position, either for or against, and develop arguments to support the position.

(c) In opinion-statement paragraphs in English, the writer tends to take his/her position, but does not argue strongly to support the position.

(d) I do not know any of the above.

II. Which of the following two paragraphs do you think is the better English paragraph?

Q11 (a) My best friend, Anne has lived an unusual life. Anne's father works for a company that sends him to foreign countries. Anne has lived in France, China, Australia, and Thailand. Anne can speak French, Chinese, and Thai.

(b) My best friend, Anne has lived an unusual life. Her father works for a company that sends him to foreign countries. Therefore, Anne has lived in France, China, Australia, and Thailand. She can speak French, Chinese, and Thai.

(c) I don't know which is better.

III.All the following paragraphs say the same things, but in different ways.

Choose the one that you think is best organized.

Q12 (a) Opera began in Italy almost 400 years ago. It soon spread to France and other European countries. Opera is a play in which most of the words are sung, not spoken. In the mid-seventeenth century, it became a popular entertainment.

(b) In the mid-seventeenth century, opera became a popular entertainment. It began in Italy almost 400 years ago. It soon spread to France and other European countries. Opera is a play in which most of the words are sung, not spoken.

(c) An opera is a play in which most of the words are sung, not spoken. It began in Italy almost 400 years ago. Opera soon spread to France and other European countries. In the mid-seventeenth century, it became a popular entertainment.

(d) I don't know which is best.

* The test was written in Japanese, except for the English texts in Q11 and 12.

** This section contained 10 test items. 